\title{
CLINICALLY NON-FUNCTIONING PITUITARY ADENOMAS
}

\section{- A 20-year single center experience}

Claudia Matta Coelho ${ }^{1}$, Rui Ramos², Rui Almeida², Olinda Marques ${ }^{1}$

${ }^{1}$ Endocrinology Department, Braga Hospital, Portugal ${ }^{2}$ Neurosurgery Department, Braga Hospital, Portugal

\section{BACKGROUND}

Clinically non-functioning pituitary adenomas (NFPAs) are the most common pituitary adenomas but their diagnosis remains challenging. Our aim is to describe clinical, imagiological and hormonal characteristics of patients with NFPAs presenting at our department.

\section{METHODS}

Retrospective review of 179 medical records of patients with NFPA at Braga Hospital from 1996 to 2016. Exclusion criteria: prolactin > $100 \mathrm{ng} / \mathrm{mL}$ or histologic evidence of prolactinoma. Statistical analysis: SPSSv20.

\section{RESULTS}

GENERAL GHARACTERISATION

179 patients

- $52 \%(n=92)$ female

- $90 \%(n=146)$ macroadenomas

- Median age: 61 years (IQR 48-73)

- Median follow-up time: 5 years (IQR 3-10)

- $64 \%(\mathrm{n}=114)$ diagnosed in the last 10 years

- Comorbidities: 40\% hypertension, 15\% T2DM

\section{INITIAL PRESENTATION}
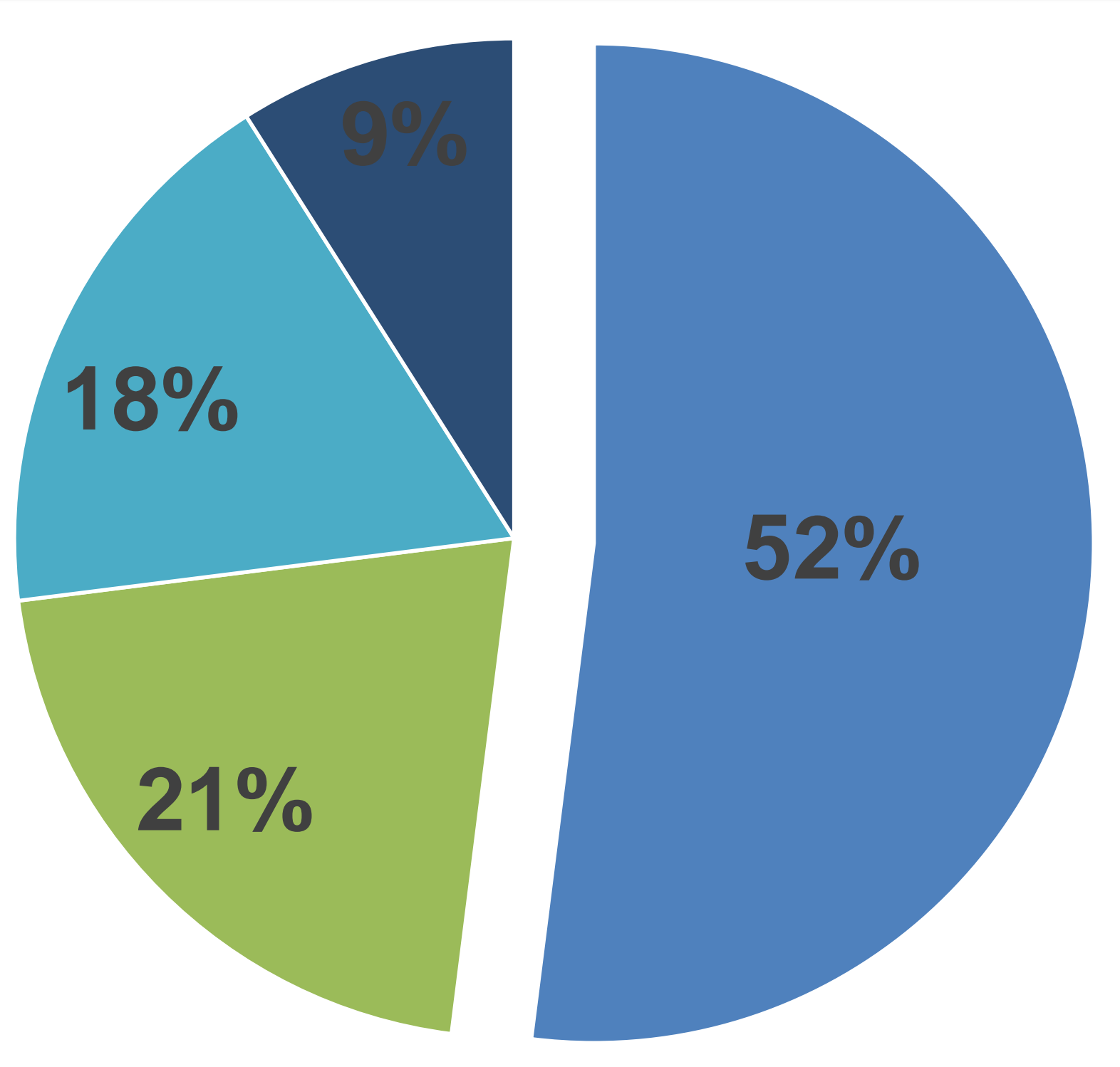

- Neuro-ophthalmologic symptoms

- Incidentalomas

- Apoplexy

- Pituitary dysfunction

Half of the patients had at least one hormonal deficiency

\begin{tabular}{|c|c|c|c|c|c|}
\hline $\begin{array}{c}\text { Pituitary } \\
\text { deficiency }\end{array}$ & LH/FSH & ACTH & TSH & GH & $\begin{array}{c}\text { Diabetes } \\
\text { Insipidus }\end{array}$ \\
\hline$\%$ & 45 & 25 & 30 & 15 & 3 \\
\hline
\end{tabular}

\section{IMAGIOLOGIC CHARACTERISTICS}

Cavernous sinus invasion

Sphenoidal sinus invasion

Suprasellar extension

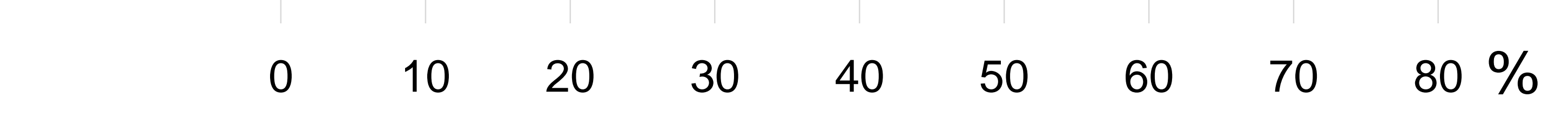

Median size $20 \mathrm{~mm}$ (IQR 13-38)

\section{HISTOLOGY}

Surgery was performed in $54 \%(n=96)$ patients

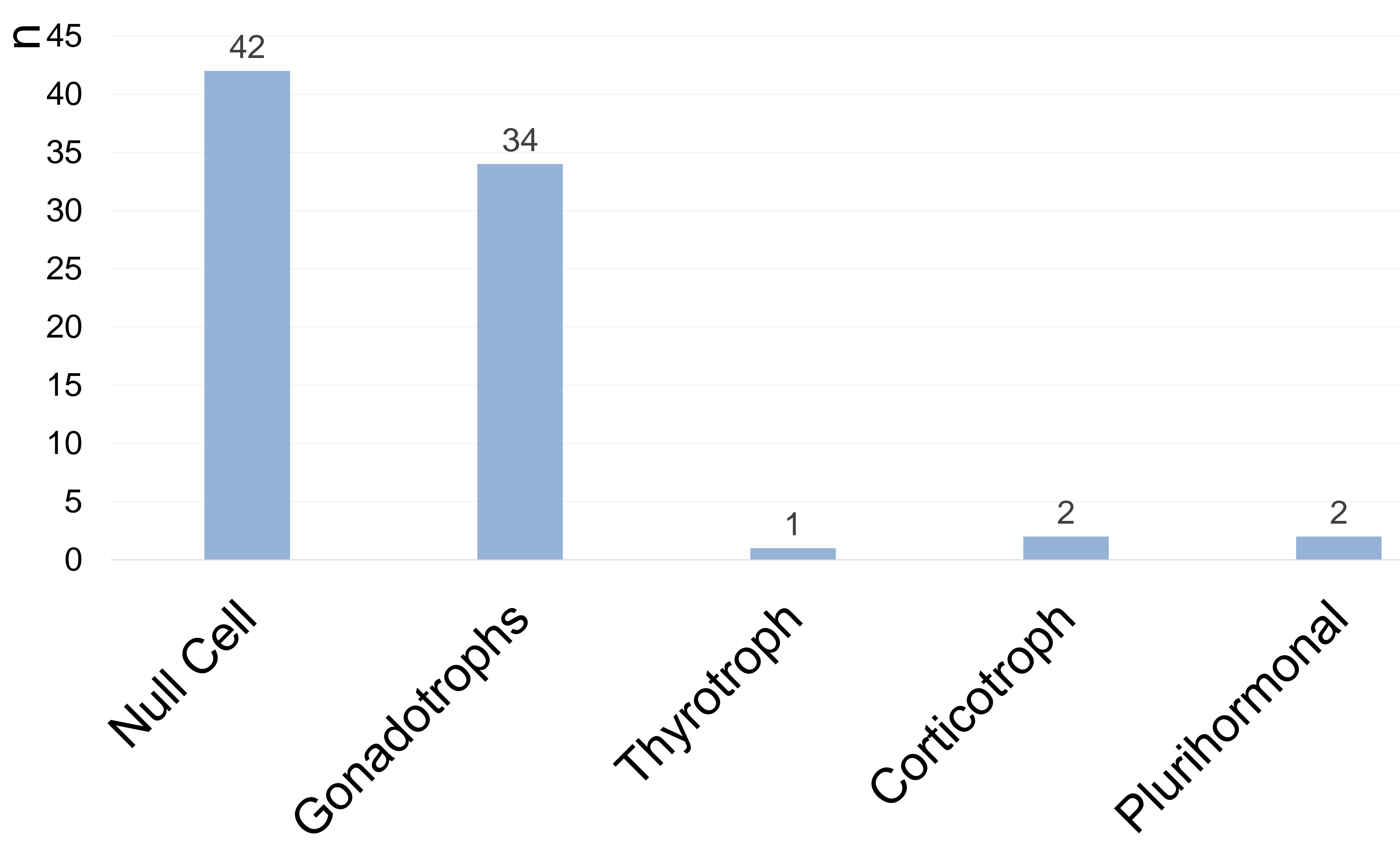

\section{DISCUSSION}

As in other series, our patients presented with visual disturbances and pituitary dysfunction at diagnosis, but we found an older population. We emphasize that $25 \%$ of patients had ACTH and $30 \%$ TSH deficiency that can cause a significant morbidity and had not been suspected before. Hence, we should be alert to clinical signs in order to an earlier diagnosis of hypopituitarism and prompt treatment. 